\title{
Corosolic acid enhances 5-fluorouracil-induced apoptosis against SNU-620 human gastric carcinoma cells by inhibition of mammalian target of rapamycin
}

\author{
HYUN SU LEE ${ }^{1 *}, J_{U N}$ BEOM PARK ${ }^{1,2 *}$, MYUNG SUN LEE ${ }^{2}$, \\ EUN YOUNG CHA ${ }^{2}$, JI YEON KIM ${ }^{1}$ and JI YOUNG SUL ${ }^{1,3}$ \\ ${ }^{1}$ Department of Surgery, Chungnam National University Hospital; ${ }^{2}$ Surgical Oncology Research Lab, \\ Chungnam National University Hospital; ${ }^{3}$ Department of Surgery, Research Institute for Medical Sciences, \\ Chungnam National University, College of Medicine, Daejeon 301-721, Republic of Korea
}

Received September 18, 2014; Accepted June 5, 2015

DOI: $10.3892 / \mathrm{mmr} .2015 .3982$

\begin{abstract}
Fluorouracil (5-FU), one of the oldest anticancer therapeutic agents, is increasingly being administered in cancer chemotherapy. In the present study, the anticancer effects of 5-FU combined with corosolic acid (CRA) were determined in SNU-620 human gastric carcinoma cells and the underlying mechanisms were examined. A combination treatment of 5-FU and CRA inhibited the viability of cells additively. Furthermore, apoptotic activity following combination treatment was found to be stronger than that of the single treatments, as observed using an Annexin V/propidium iodide assay. The protein level of Bcl-2 was decreased significantly by the combination treatment, whereas the protein level of Bim was increased. The release of mitochondrial cytochrome $c$ was increased as a result of the combination treatment, however, the combination treatment additively increased caspase- 3 and poly-(ADP-ribose) polymerase cleavages. Additionally, the mammalian target of rapamycin (mTOR) signaling pathway, which is highly activated in gastric cancer, was regulated by 5-FU and CRA, and additive mTOR/eukaryotic translation initiation factor 4E-binding protein 1 (4-EBP1) inhibition was observed with the combination treatment. Additional rapamycin treatment along with the combination treatment of 5-FU and CRA showed a more marked inhibition of mTOR/4-EBP1 in the cells, as well as increased apoptosis and antiproliferation. Thus, these data indicate that CRA enhances
\end{abstract}

Correspondence to: Professor Ji Young Sul, Department of Surgery, Research Institute for Medical Sciences, Chungnam National University, College of Medicine, 33 Munwha-ro, Daejeon 301-721, Republic of Korea

E-mail: jysul@cnu.ac.kr

*Contributed equally

Key words: gastric cancer, 5-fluorouracil, corosolic acid, mammalian target of rapamycin the anticancer activities of 5-FU via mTOR inhibition in SNU-620 human gastric carcinoma cells.

\section{Introduction}

Gastric cancer is the second most frequent cause of cancer-related mortality worldwide, and the prognosis for gastric cancer remains poor, with a five-year overall survival of just $5-15 \%$ (1). The chemotherapeutic agents commonly administered in gastric cancer treatment include 5-fluorouracil (5-FU), docetaxel, cisplatin, and Adriamycin (2,3), and the response rates to combination regimens using these therapeutic agents are $20-50 \%$, with a median survival of 6-12 months (4). However, chemotherapeutic options have become restricted due to drug resistance and severe cellular toxicity (5). Thus, there is a continuing requirement for novel therapeutic strategies to address drug resistance and toxicity, including molecularly targeted agents.

5-FU is one of the most important agents for gastrointestinal types of cancer. There are two signaling pathways by which 5-FU exerts antitumor effects; abnormal RNA processing and inhibition of DNA synthesis. 5-FU is catabolized to dihydrofluorouracil by dihydropyrimidine dehydrogenase (DPD), the first and rate-limiting enzyme of its metabolic pathway. Up to $80 \%$ of administered 5-FU is broken down by DPD in the liver (6). In tumor cells, 5-FU is functionally converted to 5-fluorodeoxyuridine monophosphate, which forms a tight covalent complex with thymidylate synthase (TS), the DNA de novo synthesizing enzyme, in the presence of the folate cofactor 5-10-methylene tetrahydrofolate (7). This complex blocks the conversion of deoxyuridine monophosphate (dUMP) to thymidine monophosphate (dTMP) and thus inhibits DNA synthesis (8). As an essential step in the biosynthesis, TS catalyses the methylation of dUMP to dTMP, and a decrease in TS levels within tumor cells blocks DNA synthesis in the dividing cells (9). The expression levels of TS in tumors have been reported as an important indicator of chemosensitivity to 5-FU (10). Thus, pharmacogenetic variability in 5-FU-associated enzymes, such as TS, may be a major determinant for treating gastrointestinal cancer patients with 5-FU (11). 
Over the past 50 years, despite there being advantages of 5-FU treatment, its clinical application has become limited by drug resistance. The overall single-agent response rate for agents, such as 5-FU, doxorubicin and methotrexate alone, in gastric carcinoma patients remains at just $10-30 \%$ (12), and the combination of 5-FU with other antitumor therapeutic agents has marginally improved the response rates to $20-50 \%$, with a median survival time of 6-12 months $(13,14)$. The development of resistance is a major problem in the administration of therapeutic agents, such as 5-FU, and limits their clinical utility (15). Thus, there is an urgent requirement to establish novel treatments for gastric cancer therapy, and resistance reversal may be achieved using combination treatments comprising existing and/or novel agents to provide an important strategy for treating gastric carcinoma.

Corosolic acid (CRA), a triterpenoid also known as $2 \alpha$-hydroxyursolic acid, is found in numerous medicinal plants, such as Lagerstroemia speciosa (banaba), Vaccinium macrocarpon (cranberry), and Weigela subsessilis (16-18). These plants are native to Asia, although CRA has also been isolated from European and South American plants (19). CRA exhibited antidiabetic activities in animal studies and clinical trials, including improvement of glucose metabolism by reducing insulin resistance in KK-Ay diabetic mice, and by lowering postchallenge plasma glucose levels in vivo, in humans $(20,21)$. CRA has demonstrated therapeutic value due its biological activities, including anti-inflammatory activity (22), as well as anti-obesity (23) and anti-atherosclerosis (24) effects.

Additionally, CRA displays anticancer activities against various human cancer cell lines. CRA induces apoptosis via a mitochondrial signaling pathway in HeLa (cervix adenocarcinoma) and MG-63 cells (osteosarcoma), and causes adenosine monophosphate-activated protein kinase activation in SNU-601 cells (stomach carcinoma) $(18,25,26)$ and HER2-downregulated cell cycle arrest in NCI-N87 cells (stomach carcinoma) (27). Furthermore, CRA causes suppression of the M2 polarization of macrophages and cell proliferation, by inhibiting signal transducer and activator of transcription 3 and nuclear factor $\kappa$-light-chain-enhancer of activated B cells activation in glioblastoma cell lines (28), as well as exerting immunosuppressive activity in myeloid-derived suppressor cells in a murine sarcoma model (29). However, the anticancer mechanism of CRA remains poorly understood.

In the present study, the additive anticancer activities of CRA are demonstrated in 5-FU-induced SNU-620 SNU-620 human gastric carcinoma cells, and the underlying mechanism is described.

\section{Materials and methods}

Materials. RPMI-1640, fetal bovine serum (FBS) and penicillin/streptomycin were obtained from GibcoLife Technologies (Carlsbad, CA, USA). Trypsin/EDTA was purchased from GE Healthcare Life Sciences (Logan, UT, USA). The following primary antibodies were used: Rabbit polyclonal anti-human caspase-3 (1:1,000; no. 9662), rabbit polyclonal anti-human poly-(ADP-ribose) polymerase (PARP) (1:1,000; no. 9542), rabbit polyclonal anti-human Bcl-2 (1:1,000; no. 2876), rabbit polyclonal anti-human mTOR (1:1,000; no. 2972), rabbit polyclonal anti-human phospho-mTOR (1:1,000; no. 2971), rabbit polyclonal anti-human 4E-binding protein 1 (4-EBP1) $(1: 1,000$; no. 9452), rabbit polyclonal anti-human phospho-4-EBP1 $(1: 1,000 ;$ no. 9455$)$ and rabbit polyclonal anti-human TS (1:1,000; no. 3766) were purchased from Cell Signaling Technology, Inc. (Danvers, MA, USA), and rabbit polyclonal anti-human Bim (1:200; sc-11425) and rabbit polyclonal antihuman GAPDH (1:1000; sc-25778) were obtained from Santa Cruz Biotechnology, Inc. (Dallas, TX, USA). Horseradish peroxidase-conjugated anti-mouse and anti-rabbit antibodies were obtained from Transduction Lab (Lexington, KY, USA). SuperSignal ${ }^{\circledR}$ West Pico Chemiluminescent Substrate was purchased from Pierce Biotechnology, Inc. (Rockford, IL, USA) and 5-FU was provided by Choongwae Pharmaceutical Co., Ltd. (Seoul, Korea). Cell Counting Kit-8 (CCK-8) was purchased from Dojindo Laboratories (Kumamoto, Japan) and the Annexin-V-FLUOS Staining kit was purchased from Roche Diagnostics GmbH (Mannheim, Germany). A Mitochondrial Apoptosis Staining kit was purchased from PromoKine $^{\circledR}$ (Heidelberg, Germany). CRA, rapamycin, resveratrol, Tris base, EDTA and all other reagents were obtained from Sigma-Aldrich (St. Louis, MO, USA).

Cells. SNU-620 human gastric carcinoma cells were purchased from the Korean Cell Line Bank (Seoul, Korea). The cells were grown in RPMI-1640 media supplemented with $10 \%$ (v/v) FBS, penicillin $(100 \mathrm{U} / \mathrm{ml}) /$ streptomycin $(100 \mu \mathrm{g} / \mathrm{ml})$ at $37^{\circ} \mathrm{C}$ in a $5 \% \mathrm{CO}_{2}$ humidified incubator.

Cell growth inhibition assay. Cells were seeded at $5 \times 10^{3}$ cells $/ \mathrm{ml}$ in 96 -well microplates and allowed to attach for $24 \mathrm{~h}$. 5-FU $(1-80 \mu \mathrm{g} / \mathrm{ml})$ or CRA $(1-100 \mu \mathrm{M})$ was added to the medium at various concentrations. Following treatment, the cell cytotoxicity and/or proliferation was assessed using the CCK-8 assay. Briefly, highly water-soluble tetrazolium salt [2-(2-methoxy-4-nitrophenyl)-3-(4-nitrophenyl) -5-(2,4-disulfophenyl)-2H-tetrazolium, monosodium salt], produced an orange-colored water-soluble product, formazan. The quantity of formazan dye generated by dehydrogenases in the cells was directly proportional to the number of living cells. CCK-8 (10 $\mu \mathrm{l})$ was added to each well and incubated for $3 \mathrm{~h}$ at $37^{\circ} \mathrm{C}$; cell proliferation and cytotoxicity were assessed by measuring the absorbance at $450 \mathrm{~nm}$ using a microplate reader (Corning, Corning, NY, USA). Three replicated wells were used per experimental condition.

Annexin V/propidium iodide (PI) staining. Cells were cultured in 6-well plates at $10^{6}$ cells/well in RPMI-1640 medium, which were pretreated with 5 -FU $(20 \mu \mathrm{g} / \mathrm{ml})$ or CRA $(50 \mu \mathrm{M})$ for $24 \mathrm{~h}$. Cells were centrifuged at $400 \mathrm{xg}$ for $5 \mathrm{~min}$ and washed three times with phosphate buffered saline (PBS), then the cell pellet was resuspended in $100 \mu \mathrm{l}$ Annexin-V-FLUOS labeling solution. Following a 30-min incubation at room temperature, the samples were analyzed using a flow cytometer (BD FACSCanto $^{\text {TM }}$ II; BD Biosciences, Franklin Lakes, NJ, USA).

Western blot analysis. Cells were incubated with 5-FU $(20 \mu \mathrm{g} / \mathrm{ml})$ or CRA $(50 \mu \mathrm{M})$ for $24 \mathrm{~h}$ and washed twice in cold PBS. The cells were lysed with lysis buffer [10 mM Tris (pH 7.4), $150 \mathrm{mM} \mathrm{NaCl}, 1 \mathrm{mM}$ EDTA, $1 \%$ Triton $\mathrm{X}-100$, $0.5 \%$ NP-40, $1 \mathrm{mM}$ PI, $1 \mathrm{mM}$ dithiothreitol, $1 \mathrm{mM}$ 

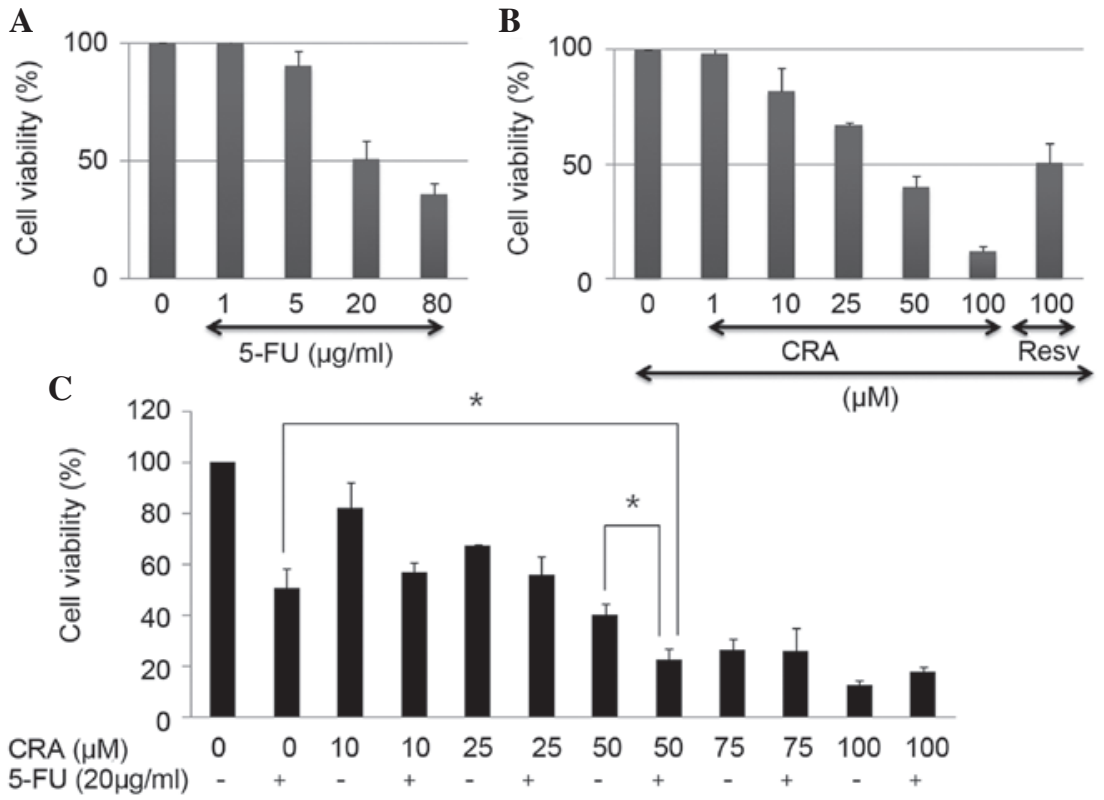

Figure 1. Antiproliferative activity of 5-FU, CRA, or a combination treatment in SNU-620 human gastric carcinoma cells. Cells were treated with increasing concentrations of either (A) 5-FU (1,5, 20 and $80 \mu \mathrm{g} / \mathrm{ml})$ or (B) CRA $(1,10,25,50$ and $100 \mu \mathrm{M})$ for $24 \mathrm{~h}$. Cell viability was determined using a Cell Counting Kit- 8 assay measuring absorbance at $450 \mathrm{~nm}$ using a 96 -well plate reader. The data are presented as the mean \pm standard deviation of three independent experiments. Resv (100 $\mu \mathrm{M})$ served as a control. (C) Cells were exposed to $20 \mu \mathrm{g} / \mathrm{ml}$ 5-FU with CRA (10-100 $\mu \mathrm{M})$ for $24 \mathrm{~h}$. All data are reported as the percentage change in comparison with the untreated control group, which was arbitrarily assigned $100 \%$ viability. ${ }^{*} \mathrm{P}<0.05$ compared with either of the single therapeutic agent-treatment groups. 5-Fu, 5-fluorouracil; CRA, corosolic acid; Resv, resveratrol.

A

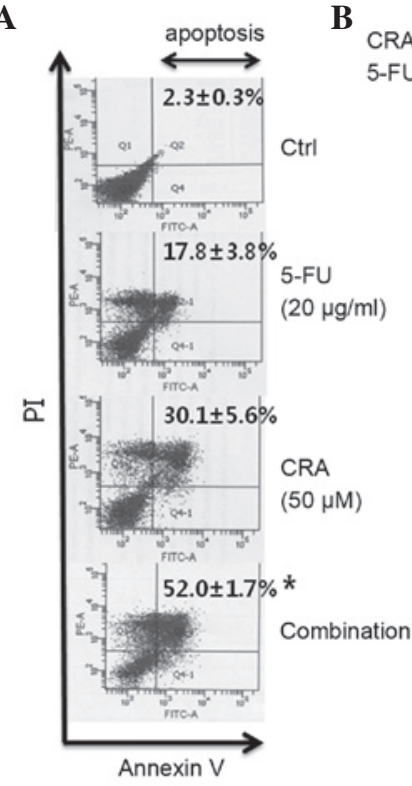
$\begin{array}{lllll}\mathrm{CRA}(50 \mu \mathrm{M}) & - & - & + & + \\ 5-\mathrm{FU}(20 \mu \mathrm{g} / \mathrm{ml}) & - & + & - & +\end{array}$

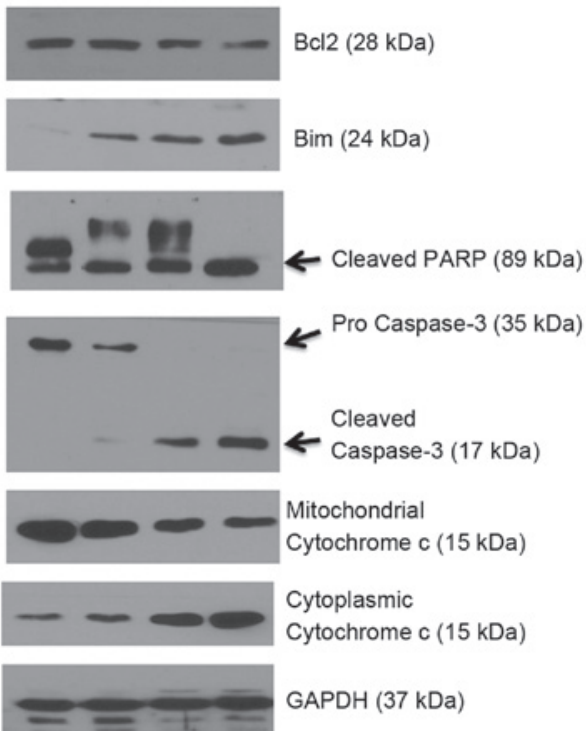

Figure 2. Apoptotic activity in SNU-620 human gastric carcinoma cells induced by 5-FU, CRA or a combination treatment. (A) Cells were treated with either 5 -FU $(20 \mu \mathrm{g} / \mathrm{ml})$ or CRA $(50 \mu \mathrm{M})$ or a combination of the two for $24 \mathrm{~h}$, and flow cytometric analysis was performed using Annexin V/PI staining. Values are presented as the mean of three independent experiments (mean \pm standard deviation). ${ }^{*} \mathrm{P}<0.05$ compared with either of the single therapeutic agent-treatment groups. (B) The expression of Bcl-2, Bim, PARP, caspase-3 and cytochrome $c$ proteins was assessed by western blot analysis. GAPDH expression served as an internal control. PI, propidium iodide; Ctrl, control; 5-FU, 5-fluorouracil; CRA, corosolic acid; PARP, poly-(ADP-ribose) polymerase.

phenylmethylsulfonyl fluoride] and placed on ice for $1 \mathrm{~h}$ with occasional vortexing. Centrifugation was then conducted at $13,000 \mathrm{xg}$ for $10 \mathrm{~min}$ and each of the cell lysates $(50 \mu \mathrm{g})$ were subjected to sodium dodecyl sulfate-polyacrylamide gel electrophoresis and transferred to polyvinylidene difluoride membranes (Invitrogen Life Technologies, Carlsbad, CA,
USA). The blots were blocked with 5\% skimmed milk in PBS containing $0.05 \%$ Tween- 20 for $1 \mathrm{~h}$ at $25^{\circ} \mathrm{C}$, then incubated with primary antibodies. This was followed by incubation with anti-rabbit or anti-mouse horseradish peroxidase-conjugated $\mathrm{IgG}$ and the blots were visualized by enhanced chemiluminescence (Pierce Biotechnology, Inc.). 
A

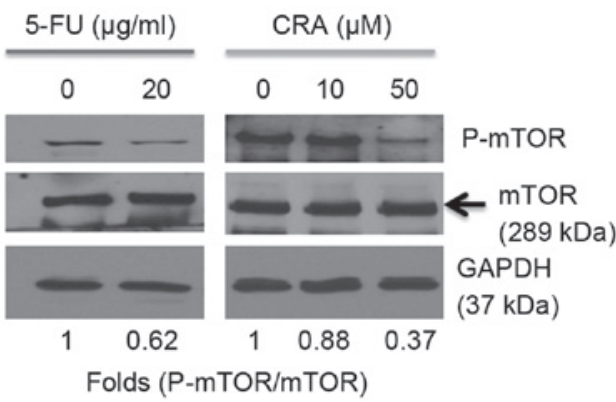

B

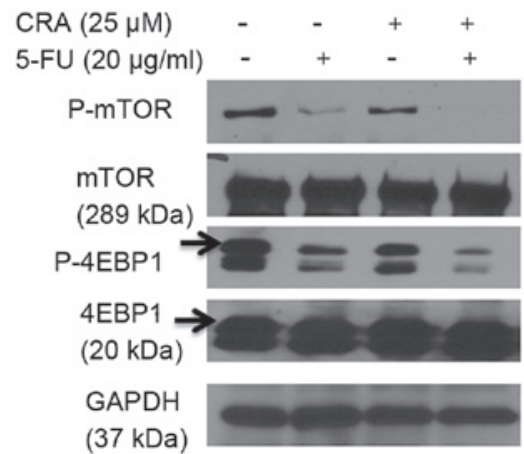

Figure 3. Decreased mTOR/4-EBP1 signaling induced by 5-FU, CRA or a combination treatment in SNU-620 human gastric carcinoma cells. Western blot analysis of the cells following treatment with (A) either 5-FU (20 $\mu \mathrm{g} / \mathrm{ml})$ or CRA $(10$ or $50 \mu \mathrm{M})$ and (B) a combination treatment $(20 \mu \mathrm{g} / \mathrm{ml} 5-\mathrm{FU}+25 \mu \mathrm{M}$ CRA) for $24 \mathrm{~h}$, equal amounts of protein samples were resolved by sodium dodecyl sulfate-polyacrylamide gel electrophoresis, followed by immunoblotting with antibodies against mTOR, P-mTOR, 4EBP1 and P-4EBP1. GAPDH expression served as an internal control. 5-FU, 5-fluorouracil; CRA, corosolic acid; $\mathrm{P}$, phosphorylated; mTOR, mammalian target of rapamycin; 4EBP1, 4E-binding protein 1.

A

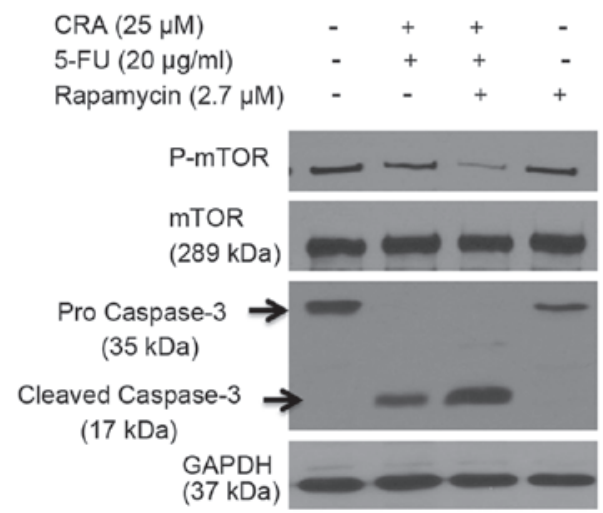

B

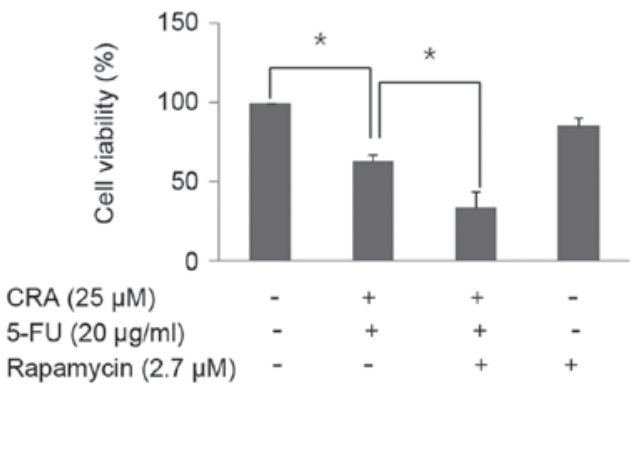

Figure 4. mTOR regulates apoptosis and growth inhibitory effects as a result of combination treatment with 5-FU and CRA in SNU-620 human gastric carcinoma cells. (A) Cells were treated with rapamycin $(2.7 \mu \mathrm{M})$ with or without the combination treatment and western blot analysis was performed using mTOR, P-mTOR and caspase-3 antibodies. GAPDH expression served as an internal control. (B) Cell growth inhibition was determined using a Cell Counting Kit- 8 assay. Values are presented as the mean of three independent experiments (mean \pm standard deviation). "P $<0.05$. CRA, corosolic acid; 5-FU, 5-fluorouracil; P, phosphorylated; mTOR, mammalian target of rapamycin.

\section{Results}

Effects of 5-FU, CRA and the combination treatment on the inhibition of cell proliferation in SNU-620 human gastric carcinoma cells. The present study was initially performed to examine whether 5-FU or CRA inhibited the growth of SNU-620 human gastric carcinoma cells. The effects of these compounds on cell proliferation were measured using the CCK-8 assay. Cells were treated with 5-FU (1, 5, 20 and $80 \mu \mathrm{g} / \mathrm{ml})$ or CRA $(1,10,25,50$ and $100 \mu \mathrm{M})$, and following a 24-h exposure, growth inhibition was measured and compared with the untreated control cells. A concentration-dependent inhibition effect on cell growth was observed (Fig. 1A and B). To assess whether there was an additive effect, proliferation was observed in the SNU-620 cells that had been exposed to 5 -FU $(20 \mu \mathrm{g} / \mathrm{ml})$ and CRA $(10,25,50,75$ and $100 \mu \mathrm{M})$ in combination (Fig. 1C). A combined treatment with $20 \mu \mathrm{g} / \mathrm{ml} 5-\mathrm{FU}$ and $50 \mu \mathrm{M}$ CRA resulted in reduced growth of SNU-620 human gastric carcinoma cells compared with that of 5-FU treatment alone; a 55.8\% reduction in proliferation was observed. No significant difference was identified in the antiproliferative effect of the combined treatments at the highest CRA concentrations (75 and $100 \mu \mathrm{M}$ ).

Apoptosis induced by 5-FU, CRA or the combination treatment in SNU-620 human gastric carcinoma cells. To investigate whether the combination of 5-FU and CRA induced apoptotic cell death more effectively than either of the treatments alone, the DNA contents were analyzed following Annexin V/PI staining by flow cytometry. Compared with each of the individual therapeutic agent-treated groups, the apoptotic proportion was increased markedly in those cells that were treated with 5-FU and CRA together (Fig. 2A). To determine the molecular basis of apoptotic cell death induced by $5-\mathrm{FU}, \mathrm{CRA}$, or the combination treatment, the cells were treated with $20 \mu \mathrm{g} / \mathrm{ml} \mathrm{5-FU}$ and $50 \mu \mathrm{M}$ CRA for $24 \mathrm{~h}$, and western blot analysis was performed to access the protein levels of the following markers of apoptosis: Bcl-2, 
Bim, caspase-3 and cleaved PARP. The protein level of Bcl-2 (a protein of the antiapoptotic family) was decreased significantly by the combination, whereas the protein level of Bim (a protein of the proapoptotic family) increased. The release of mitochondrial cytochrome $c$ increased, when compared with that of the individual treatment groups (Fig. 2B). 5-FU and CRA activated caspase- 3 and PARP, a nuclear protein cleaved by activated caspase- 3 , and a combination of the two therapeutic agents further potentiated these activities (Fig. 2B). These results demonstrate that CRA enhances 5-FU-induced apoptotic cell death in SNU-620 human gastric carcinoma cells.

Decreased mTOR/4-EBPI signaling pathway activity induced by 5-FU, CRA or the combination treatment in SNU-620 human gastric carcinoma cells. The mTOR signaling pathway is highly activated in gastric cancer, and is involved in gastric cancer cell growth and apoptosis $(30,31)$. In the present study, mTOR phosphorylation was downregulated by treatment with 5-FU or CRA alone (Fig. 3A). The combination treatment of 5-FU with CRA decreased mTOR/4-EBP1 signaling to a greater extent, when compared with the individual treatment groups (Fig. 3B).

Enhanced antiproliferative and apoptotic effects of 5-FU in combination with CRA via the mTOR signaling pathway in SNU-620 human gastric carcinoma cells. To examine whether the apoptosis and antiproliferative effect of the combination treatment of 5-FU and CRA involved inhibition of the mTOR signaling pathway, the phosphorylation levels of mTOR and 4-EBP1 were investigated by western blot analysis using the mTOR inhibitor, rapamycin (Fig. 4A). The caspase- 3 cleavage of the combination treatment was increased further with rapamycin (Fig. 4A). In addition, the antiproliferative effect of the combination treatment of 5-FU and CRA was enhanced with rapamycin (Fig. 4B). These findings indicate that $\mathrm{CRA}$ additively regulates 5-FU-induced apoptosis and viability of SNU-620 cells through the mTOR signaling pathway.

\section{Discussion}

Gastric cancer is the most common cause of cancer-related mortality in eastern Asia, with a high incidence and mortality rate. Furthermore, the survival rates of gastric cancer patients are substantially worse than those of patients with the majority of other types of cancer (32). Numerous gastric cancer patients continue to be diagnosed at a late stage, and recurrent tumors are often detected subsequent to curative surgery. For various clinical reasons, chemotherapy is an important treatment option. Among the chemotherapeutic agents, 5-FU is considered to be significant in the treatment of gastric cancer. Single-agent responses are usually partial and relatively transient, and toxicity to normal tissues has been one of the major obstacles to successful cancer chemotherapy (33). Thus, there has been increasing focus on the application of combined treatments using natural products for the treatment of gastric cancer. For example, thymoquinone, isolated from Nigella sativa seeds (34) and gambogic acid from Garcinia hanburyi trees (8) have been reported to induce anti-gastric cancer effects when combined with 5-FU. Recent studies have shown that CRA exerts anticancer activities in various cell types, including gastric cancer (18,25-29). However, to the best of our knowledge, the combined chemotherapeutic effect of 5-FU with CRA and the underlying biological mechanisms in gastric cancer have not been examined. In the present study, the additive anticancer activity of 5-FU combined with CRA in SNU-620 human gastric carcinoma cells was investigated and CRA was observed to inhibit proliferation in SNU-620 gastric cancer cells in a dose-dependent manner (Fig. 1B). It has been reported that CRA exhibits antiproliferative effects in various human gastric cancer cell lines, such as NCI-N87, SNU-484, and SNU-601, with half maximal inhibitory concentration $\left(\mathrm{IC}_{50}\right)$ values for CRA between 16.9 and $43.7 \mu \mathrm{M}(18,27)$. In the current study, in SNU-620 human gastric carcinoma cells, the $\mathrm{IC}_{50}$ value determined for CRA $(40.6 \mu \mathrm{M})$ was within this range. The results revealed that 5 -FU-induced proliferative reduction was synergistically enhanced as a result of combination treatment with CRA (50 $\mu \mathrm{M}$; Fig. 1C).

Apoptosis is a tightly regulated signaling process that involves the coordination of antiapoptotic and proapoptotic proteins (35). In the present study, apoptosis in gastric cancer cells induced by 5-FU and CRA was investigated using Annexin V/PI staining. The results demonstrated that 5-FU combined with CRA induced apoptosis in SNU-620 human gastric carcinoma cells more markedly than either 5-FU or CRA alone (Fig. 2A). 5-FU and CRA combination treatment resulted in a decrease in Bcl-2 expression, an increase in Bim protein expression, and release of cytochrome $c$ from the mitochondria into the cytoplasm. Additionally, caspase-3 and PARP activation were observed with 5-FU and CRA induction in the SNU-620 human gastric carcinoma cells (Fig. 2B). These results demonstrate that CRA exposure may potentiate apoptosis induced by 5 -FU with mitochondrial dysfunction, and indicates that CRA may be an effective adjuvant treatment with 5-FU.

mTOR, a serine/threonine kinase protein (290 kDa), has been considered as a potential target in cancer therapy. mTOR is a member of the phosphatidylinositol-3-kinase (PI3K) family and appears to operate downstream of PI3K/Akt (36). Major functions of mTOR include the activation of p70 S6 kinase (S6K) and inhibition of 4-EBP1. Activation of S6K leads to translation of ribosomal proteins and ribosome biogenesis, and the inhibition of 4-EBP1 results in inhibition of eukaryotic translation initiation factor 4E, as well as activation of cap-dependent translation of critical mRNAs (2). The activation of mTOR results in the control of protein synthesis, metabolism, proliferation, growth and apoptosis (37). The mTOR inhibitor, rapamycin is an approved therapeutic agent for preventing allograft rejection in organ transplantation due to its potent inhibition of T-cell activation; furthermore, rapamycin exhibits anticancer activity against various types of cancer $(4,30,31)$. The mTOR signaling pathway is highly activated in gastric cancers and presents a promising novel molecular target for cancer therapy; thus, mTOR inhibitors may act effectively against gastric cancer cells (30). It has been reported that mTOR inhibition is necessary to enhance 5-FU-induced apoptosis in gastric cancer cells (38), and CRA also regulates mTOR signaling in gastric cancer cells, 
leading to cell viability reduction (18). In the present study, 5-FU in combination with CRA was assessed to establish whether this treatment combination inhibited cell viability through the mTOR signaling pathway in gastric cancer cells. The results indicate that $20 \mu \mathrm{g} / \mathrm{ml} 5$-FU markedly decreases mTOR phosphorylation and signaling (Fig. 3A), and the additive activity of mTOR/4-EBP1 signaling was observed by administering $25 \mu \mathrm{M}$ CRA (Fig. 3B). Additional rapamycin treatment showed increasingly potent inhibition of mTOR phosphorylation, apoptosis and cell proliferation (Fig. 4A and B). In the present study, combination chemotherapy using an anticancer drug (5-FU) and a natural compound (CRA), which exhibited cell signal inhibitory activity achieved an improved response rate by affecting cell viability.

In conclusion, the present results demonstrate that the anticancer effect of 5-FU combined with CRA was more marked than treatment with 5-FU or CRA alone. It was found that apoptotic and antiproliferative effects were induced, when the two therapeutic agents were used in combination, via the mTOR/4-EBP1 signaling pathway. These findings indicate the potential combined application of these therapeutic agents in adjuvant clinical treatment of gastric cancer.

\section{Acknowledgements}

The present study was supported by the research fund of Chungnam National University (Daejeon, Korea).

\section{References}

1. Shigematsu H, Yoshida K, Sanada Y, Osada S, Takahashi T, Wada Y, Konishi K, Okada M and Fukushima M: Rapamycin enhances chemotherapy-induced cytotoxicity by inhibiting the expressions of TS and ERK in gastric cancer cells. Int J Cancer 126: 2716-2725, 2010.

2. Ohtsu A: Chemotherapy for metastatic gastric cancer: Past, present and future. J Gastroenterol 43: 256-264, 2008.

3. Ajani JA, Moiseyenko VM, Tjulandin S, Majlis A, Constenla M, Boni C, Rodrigues A, Fodor M, Chao Y, Voznyi E, et al; V-325 Study Group: Clinical benefit with docetaxel plus fluorouracil and cisplatin compared with cisplatin and fluorouracil in a phase III trial of advanced gastric or gastroesophageal cancer adenocarcinoma: The V-325 Study Group. J Clin Oncol 25 3205-3209, 2007.

4. Lee KH, Hur HS, Im SA, Lee J, Kim HP, Yoon YK, Han SW, Song SH, Oh DY, Kim TY, et al: RAD001 shows activity against gastric cancer cells and overcomes 5-FU resistance by downregulating thymidylate synthase. Cancer Lett 299: 22-28, 2010.

5. Benson AB III: New approaches to the adjuvant therapy of colon cancer. Oncologist 11: 973-980, 2006.

6. Longley DB, Harkin DP and Johnston PG: 5-fluorouracil: Mechanisms of action and clinical strategies. Nat Rev Cancer 3: 330-338, 2003

7. Sasaki E, Tominaga K, Kuwamura H, Watanabe T, Fujiwara Y, Oshitani N, Higuchi K and Arakawa T: Synergistic antitumor effect of combined 5-fluorouracil (5-FU) with 5-chloro-2,4-dihydroxypyridine on 5-FU-resistant gastric cancer cells: Possible role of a dihydropyrimidine dehydrogenase-independent mechanism. J Gastroenterol 42: 816-822, 2007.

8. Wang J, Liu W, Zhao Q, Qi Q, Lu N, Yang Y, Nei FF, Rong JJ, You QD and Guo QL: Synergistic effect of 5-fluorouracil with gambogic acid on BGC-823 human gastric carcinoma. Toxicology 256: 135-140, 2009.

9. Parker WB and Cheng YC: Metabolism and mechanism of action of 5-fluorouracil. Pharmacol Ther 48: 381-395, 1990.

10. Peters GJ, van der Wilt CL, van Triest B, Codacci-Pisanelli G, Johnston PG, van Groeningen CJ and Pinedo HM: Thymidylate synthase and drug resistance. Eur J Cancer 31: 1299-1305, 1995.
11. Papamichael D: The use of thymidylate synthase inhibitors in the treatment of advanced colorectal cancer: Current status. Stem Cells 18: 166-175, 2000.

12. Murad AM, Santiago FF, Petroianu A, Rocha PR, Rodrigues MA and Rausch M: Modified therapy with 5-fluorouracil, doxorubicin and methotrexate in advanced gastric cancer. Cancer 72: 37-41, 1993.

13. Douillard JY, Cunningham D, Roth AD, Navarro M, James RD, Karasek P, Jandik P, Iveson T, Carmichael J, Alakl M, et al: Irinotecan combined with fluorouracil compared with fluorouracil alone as first-line treatment for metastatic colorectal cancer: A multicentre randomised trial. Lancet 355: 1041-1047, 2000.

14. Chon HJ, Rha SY, Im CK, Kim C, Hong MH, Kim HR, An JR, Noh SH, Chung HC and Jeung HC: Docetaxel versus paclitaxel combined with 5-FU and leucovorin in advanced gastric cancer: combined analysis of two phase II trials. Cancer Res Treat 41: 196-204, 2009.

15. Choi EJ and Kim GH: 5-Fluorouracil combined with apigenin enhances anticancer activity through induction of apoptosis in human breast cancer MDA-MB-453 cells. Oncol Rep 22: 1533-1537, 2009.

16. Hou W, Li Y, Zhang Q, Wei X, Peng A, Chen L and Wei Y: Triterpene acids isolated from Lagerstroemia speciosa leaves as alpha-glucosidase inhibitors. Phytother Res 23: 614-618, 2009.

17. Kim E, Sy-Cordero A, Graf TN, Brantley SJ, Paine MF and Oberlies NH: Isolation and identification of intestinal CYP3A inhibitors from cranberry (Vaccinium macrocarpon) using human intestinal microsomes. Planta Med 77: 265-270, 2011.

18. Lee MS, Lee CM, Cha EY, Thuong PT, Bae K, Song IS, Noh SM and Sul JY: Activation of AMP-activated protein kinase on human gastric cancer cells by apoptosis induced by corosolic acid isolated from Weigela subsessilis. Phytother Res 24: 1857-1861, 2010.

19. Stohs SJ, Miller H and Kaats GR: A review of the efficacy and safety of banaba (Lagerstroemia speciosa L.) and corosolic acid. Phytother Res 26: 317-324, 2012.

20. Miura T, Ueda N, Yamada K, Fukushima M, Ishida T, Kaneko T, Matsuyama F and Seino Y: Antidiabetic effects of corosolic acid in KK-Ay diabetic mice. Biol Pharm Bull 29: 585-587, 2006.

21. Fukushima M, Matsuyama F, Ueda N, Egawa K, Takemoto J, Kajimoto Y, Yonaha N, Miura T, Kaneko T, Nishi Y, et al: Effect of corosolic acid on postchallenge plasma glucose levels. Diabetes Res Clin Pract 73: 174-177, 2006.

22. Banno N, Akihisa T, Tokuda H, Yasukawa K, Higashihara $H$, Ukiya M, Watanabe K, Kimura Y, Hasegawa J and Nishino H: Triterpene acids from the leaves of Perilla frutescens and their anti-inflammatory and antitumor-promoting effects. Biosci Biotechnol Biochem 68: 85-90, 2004.

23. Zong W and Zhao G: Corosolic acid isolation from the leaves of Eriobotrta japonica showing the effects on carbohydrate metabolism and differentiation of 3T3-L1 adipocytes. Asia Pac J Clin Nutr 16: 346-352, 2007.

24. Chen H, Yang J, Zhang Q, Chen LH and Wang Q: Corosolic acid ameliorates atherosclerosis in apolipoprotein E-deficient mice by regulating the nuclear factor- $\kappa \mathrm{B}$ signaling pathway and inhibiting monocyte chemoattractant protein-1 expression. Circ J 76: 995-1003, 2012.

25. Xu Y, Ge R, Du J, Xin H, Yi T, Sheng J, Wang Y and Ling C: Corosolic acid induces apoptosis through mitochondrial pathway and caspase activation in human cervix adenocarcinoma HeLa cells. Cancer Lett 284: 229-237, 2009.

26. Cai X, Zhang H, Tong D, Tan Z, Han D, Ji F and Hu W: Corosolic acid triggers mitochondria and caspase-dependent apoptotic cell death in osteosarcoma MG-63 cells. Phytother Res 25: 1354-1361, 2011.

27. Lee MS, Cha EY, Thuong PT, Kim JY, Ahn MS and Sul JY: Down-regulation of human epidermal growth factor receptor $2 /$ neu oncogene by corosolic acid induces cell cycle arrest and apoptosis in NCI-N87 human gastric cancer cells. Biol Pharm Bull 33: 931-937, 2010.

28. Fujiwara Y, Komohara Y, Ikeda T and Takeya M: Corosolic acid inhibits glioblastoma cell proliferation by suppressing the activation of signal transducer and activator of transcription-3 and nuclear factor-kappa B in tumor cells and tumor-associated macrophages. Cancer Sci 102: 206-211, 2011. 
29. Horlad H, Fujiwara Y, Takemura K, Ohnishi K, Ikeda T, Tsukamoto $\mathrm{H}$, Mizuta $\mathrm{H}$, Nishimura $Y$, Takeya $M$ and Komohara Y: Corosolic acid impairs tumor development and lung metastasis by inhibiting the immunosuppressive activity of myeloid-derived suppressor cells. Mol Nutr Food Res 57: 1046-1054, 2013.

30. Lang SA, Gaumann A, Koehl GE, Seidel U, Bataille F, Klein D, Ellis LM, Bolder U, Hofstaedter F, Schlitt HJ, et al: Mammalian target of rapamycin is activated in human gastric cancer and serves as a target for therapy in an experimental model. Int J Cancer 120: 1803-1810, 2007.

31. Matsuzaki T, Yashiro M, Kaizaki R, Yasuda K, Doi Y, Sawada T, Ohira M and Hirakawa K: Synergistic antiproliferative effect of mTOR inhibitors in combination with 5 -fluorouracil in scirrhous gastric cancer. Cancer Sci 100: 2402-2410, 2009.

32. Jackson C, Cunningham D and Oliveira J; ESMO Guidelines Working Group: Gastric cancer: ESMO clinical recommendations for diagnosis, treatment and follow-up. Ann Oncol 20 (Suppl 4): 34-36, 2009.
33. Glimelius B, Ekström K, Hoffman K, Graf W, Sjödén PO, Haglund U, Svensson C, Enander LK, Linné T, Sellström H, et al: Randomized comparison between chemotherapy plus best supportive care with best supportive care in advanced gastric cancer. Ann Oncol 8: 163-168, 1997.

34. Lei X, Lv X, Liu M, Yang Z, Ji M, Guo X and Dong W: Thymoquinone inhibits growth and augments 5-fluorouracil-induced apoptosis in gastric cancer cells both in vitro and in vivo. Biochem Biophys Res Commun 417: 864-868, 2012.

35. Tang D, Lotze MT, Kang R and Zeh HJ: Apoptosis promotes early tumorigenesis. Oncogene 30: 1851-1854, 2011

36. Bjornsti MA and Houghton PJ: The TOR pathway: A target for cancer therapy. Nat Rev Cancer 4: 335-348, 2004.

37. Wullschleger S, Loewith R and Hall MN: TOR signaling in growth and metabolism. Cell 124: 471-484, 2006.

38. Tomioka H, Mukohara T, Kataoka Y, Ekyalongo RC, Funakoshi Y, Imai Y, Kiyota N, Fujiwara Y and Minami H: Inhibition of the mTOR/S6 K signal is necessary to enhance fluorouracil-induced apoptosis in gastric cancer cells with HER2 amplification. Int J Oncol 41: 551-558, 2012. 